\title{
Numerical Investigation of Bushfire-Wind Interaction and its Impact on Building Structure
}

\author{
YAPING HE ${ }^{1}$, KENNY C.S. KWOK ${ }^{1}$, GRAHAME B. DOUGLAS ${ }^{1,2}$, and IKHWAN M. RAZALI ${ }^{1}$ \\ ${ }^{1}$ School of Engineering, \\ University of Western Sydney \\ Penrith, NSW 2751, Australia \\ ${ }^{2}$ NSW Rural Fire Service \\ Granville, NSW 2142, Australia
}

\begin{abstract}
Presented in this paper are the results of a numerical study on bushfire, wind and structure interactions. The association of bushfires with wind has long been recognized. However, the mechanism of their interaction has not received due attention. In the current study a computational fluid dynamics package was used to reveal the enhancement of wind by fires at scales comparable to buildings and the impact on buildings. The study also revealed a pulsation movement of flames under the influence of free stream wind conditions. The predicted pressure coefficient distribution around a building under no-fire condition was compared with the experimental result measured by others. Reasonably good agreement was obtained before a fire was added to reveal the impact of the fire.
\end{abstract}

KEYWORDS: CFD, modeling, pressure coefficient, pulsation, velocity, wildfires.

\section{NOMENCLATURE LISTING}

\begin{tabular}{|c|c|c|c|}
\hline$C_{p}$ & pressure coefficient & $W$ & width of fire bed (m) \\
\hline$E(f)$ & $\begin{array}{l}\text { normalized power spectrum (energy fraction } \\
\text { at given frequency) (s) }\end{array}$ & $x, y, z$ & $\begin{array}{l}\text { coordinates of the computational } \\
\text { domain }(\mathrm{m})\end{array}$ \\
\hline$f$ & frequency $(\mathrm{Hz})$ & Greek & \\
\hline$g$ & gravitational constant $\left(9.8 \mathrm{~m} / \mathrm{s}^{2}\right)$ & $\delta$ & grid cell size (m) \\
\hline$H$ & height of building block (m) & $\mu$ & mean \\
\hline$I$ & turbulence intensity & $\rho$ & density $\left(\mathrm{kg} / \mathrm{m}^{3}\right)$ \\
\hline$Q$ & heat release rate $(\mathrm{kW})$ & $\sigma$ & standard deviation \\
\hline$Q_{m}$ & bushfire intensity $(\mathrm{kW} / \mathrm{m})$ & \multicolumn{2}{|c|}{ superscripts } \\
\hline$s$ & $\begin{array}{l}\text { distance around the perimeter of building } \\
\text { block }(\mathrm{m})\end{array}$ & & $\begin{array}{l}\text { normalized non-dimensional } \\
\text { quantity }\end{array}$ \\
\hline$T$ & temperature $(\mathrm{C}, \mathrm{K})$ & $\wedge$ & maximum value \\
\hline$t$ & time $(s)$ & \multicolumn{2}{|c|}{ subscripts } \\
\hline$V$ & total velocity $\left(=\sqrt{u^{2}+v^{2}+w^{2}}, \mathrm{~m} / \mathrm{s}\right)$ & $\infty$ & ambient \\
\hline$u, v, w$ & velocity components in $x, y$ and $z$ directions & $r$ & reference value \\
\hline
\end{tabular}

\section{INTRODUCTION}

Bushfires or wildland fires are a frequent and inevitable aspect of the landscape of many countries. The pattern of bushfire occurrence is strongly associated with adverse weather conditions [1]. Most bushfires are dealt with and controlled by the various fire services at their early stages of development. Severe fire events that can cause major losses to life, property and the environment are less common, but nonetheless occur with some regularity. They are erratic in nature and of high intensity, making control difficult.

Bushfire protection studies may be generally categorized into two closely related areas: (1) the relationship between bushfire severity and the environmental conditions; and (2) the mechanism of damage by bushfires. In the first area, three key elements in the development of major bushfires have been identified in the literature [2], namely: fuel, weather and terrain. Severe bushfires occur as single or concurrent fires under conditions of high fuel loads (vegetation), severe weather and relief (topography). The study into these key elements has been the focus of many researchers [3]. In particular, the impacts of weather 
condition on fire risk, fire intensity and rate of fire spread have been documented [2, 4-6]. Progress has also been made in the area of bushfire attack mechanism [7] with focus on embers, radiant heat and flame contact. However, little has been developed to consider the effects of fire-generated or -enhanced winds. Construction practice, as applied through building codes and standards $[8,9]$, provides some opportunities for improved building resilience in the face of bushfire attack. However, wind loading does not form part of the design and assessment processes. This is, perhaps, due to inadequate understanding of fire, wind and structure interactions. This paper seeks to provide a model for understanding the phenomena of fireinduced winds which may lead to the development of improved practice for the protection of buildings from fire-induced wind storms.

\section{NATURE OF BUSHFIRE WEATHER CONDITIONS AND BUSHFIRE ATTACK}

Factors that characterize severe bushfire events in Australia include [10] antecedent rainfall deficit which results in low fuel moisture (for forest fires) and strong hot gusty winds associated with synoptic weather patterns.

The role of wind in such adverse conditions is by its very nature a complex aspect of the bushfire phenomenon. Ambient wind conditions are a major driver of fire behavior in terms of rates of spread, fire intensity and flame characteristics. Wind also supports the transport of burning embers or brands significant distances to push the fire ahead of the fire front or to vulnerable parts of buildings, thereby increasing building vulnerability to bushfire attack [6]. As such, wind speed is given a significant weighting in the evaluation of the Fire Danger Index (FFDI) [6].

It has been generally determined that the majority of losses arising from bushfire events occur within distances of up to $100 \mathrm{~m}$ from the bush $[11,12]$ although in some cases these distances have extended to in excess of $250 \mathrm{~m}$ [13]. Although surveys on the mechanism of damage by bushfires in Australia can be dated back to the early part of the last century [14], it was not until late last century that the potential role of severe winds was recognized. After completing their review of Ash Wednesday fire in 1983 in Australia, Ramsay et al. [15] concluded that wind had "played a role in damaging houses, breaking windows, blowing roofs off. In some cases the wind did more damage than the fires." It was not until 2001 that winds were again seen as a significant attack mechanism [16]. However, a clear framework for application to construction practice has not yet been developed.

In 2009, after the devastation of the 7 February 2009 bushfires in Victoria, Australia, a substantial effort was made to extensively survey 1600 of the over 2000 houses lost or damaged during these fire events. The role of wind was noted as a small contributor to loss/damage although 135 lost/damaged houses attributed 'fire and wind' as a likely cause of the house fire [17]. Interestingly, some $33 \%$ were identified as 'fire damage, wind unknown' and a small number exhibited wind only effects arising from the fires. This is in strong contrast to the observed dislodgement of un-burnt roofing elements from burnt out structures [17]. Some confusion persists about the role of wind in the destruction of houses and inconsistency in evaluation. This may be partly attributed to the inconsistencies in the survey format and in the skills of data collectors.

During the Victorian bushfires, ambient average wind speeds measured at stations some distance from the fires only rarely exceeded $60 \mathrm{~km} / \mathrm{h} \mathrm{[18].} \mathrm{Such} \mathrm{wind} \mathrm{velocities} \mathrm{cannot} \mathrm{by} \mathrm{themselves} \mathrm{be} \mathrm{attributed} \mathrm{to} \mathrm{as} \mathrm{the}$ cause of wind damage to structures. Wind speeds in excess of $115 \mathrm{~km} / \mathrm{h}$ are normally required for widespread and significant building damage.

It is often observed in discussion with operational firefighters and from film footages that stronger winds than forecasted can be associated with the passage of the fire. Extensive and intense thermal energy released by bushfires can give rise to dramatic pyro-convection plume as seen during the 2009 Victoria fires. The resultant plume can cause damages that have been rated at an equivalence of F-2 on the Fujita Tornado Intensity Scale [19], with wind speeds of between 51-70 m/s $(180-250 \mathrm{~km} / \mathrm{h})$.

\section{NUMERICAL SIMULATION OF WIND-FIRE-BUILDING INTERACTIONS}

\section{Overview}

The phenomenon of wind and fire plume interactions at large scales up to a few hundred meters or even kilometers above the ground has attracted attention of researchers for many years [4,19-21]. In a relatively 
recent study, Cunningham et al. [22] investigated vortex formation of buoyant plumes generated from wildland fires of circular or elliptical ring sources. The dimension of their computation domain was in the order of kilometers and the grid size was $10 \mathrm{~m}$, in the same order as building size. In a numerical simulation study, Coen [23] noted the opposing effect of fire generated wind on fire spread when there is no natural wind. Again, the grid size used in her work was in the order of $100 \mathrm{~m}$. The large scale studies help the understanding of the meteorological impact of bushfires but could not help resolving issues related to buildings. At a relatively smaller scale, or at the near ground level scale, focus has been directed towards the influence of wind on fire spread [24,25]. Little attention has been given to the study of the influence of bushfire on wind and the consequential impact on building structures using domain sizes comparable to buildings and grid sizes significantly smaller than the boundary layer thickness until recently.

In 2009, Hostikka et al. [26] reported a numerical investigation of fires at wildland urban interface using domain size in the order of tens of meters and grid size down to $6.25 \mathrm{~cm}$. The aim of their study was to compare 2-D and 3-D simulations and the scope was limited to the investigation of the thermal impact of bushfire on a building. It was recommended, based on their study, that 3-D simulations should be used for accurate predictions of building and human responses, and the grid size of $0.25 \mathrm{~m}$ is adequate for thermal radiation calculations. The issues of wind-fire-structure interaction was raised by Douglas et al. in a recent presentation [27] followed by further discussion of a preliminary study of the aerodynamic impact of fire enhanced wind on building structure by Kwok et al. [28]. However, whilst the study revealed some interesting results, the gird size in their work was $0.5 \mathrm{~m}$, and a finer grid resolution was found to be necessary to produce a reasonable comparison with field experimental data without fire. The current study is a continuation of the work adopting a finer grid and including direct comparisons of the numerically computed aerodynamic results with field experimental data.

Bushfires can be regarded as energy sources which inject thermal energy into the atmosphere at ground level. This injection of thermal energy causes air near the combustion region to expand and density to decrease, whereby buoyancy flux is created inducing hot air to rise upwards. Meanwhile, the relatively cold air is drawn in to replenish the uprising hot air. The interaction of the momentum flux carried by wind and the buoyancy flux could exacerbate the wind conditions and cause detrimental effects on building structures.

A computational fluid dynamics (CFD) study of wind and bushfire interaction at the scale comparable to building dimensions has been conducted to investigate the aerodynamic impact of fire-enhanced wind on a building. The computer program used is the Fire Dynamics Simulator 5 (FDS5) [29] developed at the National Institute of Standards and Technology, USA The software solves numerically a form of the Navier-Stokes equations appropriate for low-speed, thermally-driven flow with an emphasis on smoke and heat transport from fires. It has the capability of employing either large eddy simulation (LES) scheme or direct numerical simulation (DNS) scheme to resolve turbulence flows. The core algorithm is an explicit predictor-corrector scheme with second order accuracy in space and time [30]. When the LES scheme is employed, the turbulence effect at the sub-grid level is modelled by a type of Smagorinsky $k-\varepsilon$ model as described in Ref. [30]. The LES scheme is employed in the current study.

The numerical investigation was undertaken in two steps. Firstly, the interaction between fire and wind alone was studied. Then a building block was added to the flow field downstream of the fire front to see the impact of the fire enhanced wind on the building structure.

\section{Model Set-Up and Simulation Control}

The computation domain was a $40 \times 30 \times 18 \mathrm{~m}$ rectangular space, as shown in Fig. 1 . The fire front of a bushfire was simulated with a two dimensional fire bed which is $3 \mathrm{~m}$ in width and runs across the entire domain in the $y$-direction at the ground level $(z=0 \mathrm{~m})$. This approach is a quasi two-dimensional approach. The bushfire front was assumed infinitely long. The two domain boundaries in the $y$-direction were closed and assumed slip conditions. In other words, the domain was a small section of a much wider fire front and yet it was wide enough to allow three-dimensional flow computations. The origin of the coordinates was set at the trailing edge of fire bed. The far left boundary of the domain is at $x=-5.0 \mathrm{~m}$. The grid size was varied from $0.5 \times 0.5 \times 0.5 \mathrm{~m}$ to $0.16 \times 0.24 \times 0.15 \mathrm{~m}$ in different simulation scenarios. The fire front was assumed to be stationary. A building block of $6 \mathrm{~m}$ cube was added to the domain at the distance of $20 \mathrm{~m}$ downstream of the fire front. 
For computation economy, the radiation calculation was switched off during simulations. As such, the default fraction of 0.35 was taken out of the specified total heat release rates.

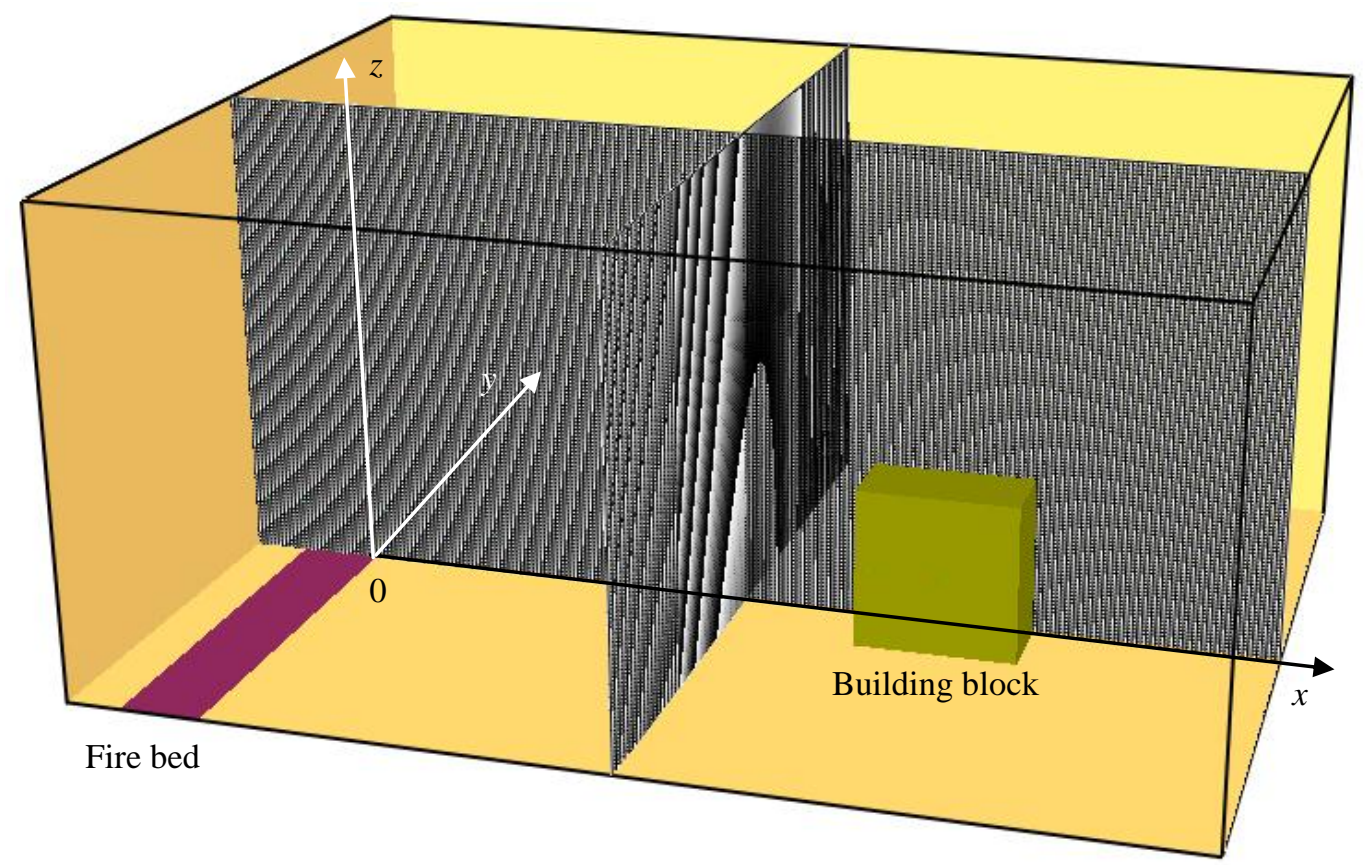

Fig. 1. Computational domain and grid set-up.

A number of expressions exist in the literature to describe wind velocity profiles. Cunningham et al. [22] used a hyperbolic tangential function, whereas Hostikka et al. [26] used a power function. In the current study the power function of the form

$U_{0}^{*}\left(z^{*}\right)=u_{0}^{*}\left(z^{*}\right)=\left(z^{*}\right)^{\alpha}$

was specified at the boundary of $x=0 \mathrm{~m}$, where:

$u_{0}^{*}(z *)=\frac{u_{0}\left(z^{*}\right)}{u_{r}} \quad$ and $\quad z^{*}=\frac{z}{z_{r}}$

The value of $\alpha$ is 0.16 . Wind was blowing from left to right along the positive $x$-direction. This profile is based on field measurement of mean velocities of a fully developed boundary layer of turbulent wind near ground. A comparison of Eq. 1 with the field measurement data is presented in the section Wind-FireStructure Interactions of the current paper. It is noted that the specified velocity profile did not contain instantaneous fluctuating component. Notwithstanding this, the fire source in the computation domain acted as a dominant trip or disturbance that enhances turbulence development along the $25 \mathrm{~m}$ fetch between the left boundary and the building block.

All solid surfaces in the computation domain were assumed smooth. As such, the Werner-Wengle wall model is applied for the velocity profile in the near wall region [29,30]. Slip conditions were specified at the two domain boundaries in $y$-direction $(y=-15 \mathrm{~m}$ and $y=15 \mathrm{~m})$ by setting FREE_SLIP=.TRUE. at YMIN and YMAX [29]. The boundaries at the right $(x=35 \mathrm{~m})$ and top $(z=18 \mathrm{~m})$ were specified as 'OPEN'.

It has been suggested that for reasonable accuracy, the ratio of the characteristic fire diameter to the grid size, $D * / \delta$, is better in the range between 4 and 16 [29]. The evaluation of the characteristic fire diameter relies on the use of total heat release rate $Q$ : 
$D^{*}=\left(\frac{Q}{\rho_{\infty} C_{p} T_{\infty} \sqrt{g}}\right)^{\frac{2}{5}}$

Since the fire source in the current study was stretched in one direction, the diffusion and air-fuel mixing are driven primarily by parameter gradients in $x$-direction. It is therefore plausible to use the heat release rate over an area characterized by the dimension of the fire front width.

$Q=Q_{m} W$

The minimum bushfire intensity used in the current study was $3000 \mathrm{~kW} / \mathrm{m}$. The minimum heat release rate corresponding to the fuel bed width of $3 \mathrm{~m}$ is $9 \mathrm{MW}$ and the resulting minimum characteristic fire diameter is $2.3 \mathrm{~m}$. The fire diameter to cell size ratio varied between 4.6 to 15 in the current study.

The initial time step size was set according to the default value based on the correlation [29]

$$
D T=5(\delta x \delta y \delta z)^{1 / 3}(g Z)^{-1 / 2}
$$

where $Z$ is the height of the computation domain.

All simulations were executed for $130 \mathrm{~s}$ and the output (sampling) frequency was $10 \mathrm{~Hz}$.

\section{Fire and Wind Interaction}

In the simulation scenario to study the fire and wind interaction, the reference height $z_{r}$ and reference velocity $u_{r}$ were $10 \mathrm{~m}$ and $5 \mathrm{~m} / \mathrm{s}$ respectively. The fire intensity was $3 \mathrm{MW} / \mathrm{m}$. The corresponding heat release rate per unit area was $1 \mathrm{MW} / \mathrm{m}^{2}$. These input parameters represent a moderate wind and fire conditions. The grid size for this simulation was $0.17 \times(0.24 / 0.46) \times 0.15 \mathrm{~m}$. See subsection Grid Dependence Study for more description of the grid system.

Presented in Fig. 2 is a coloured temperature slice at $y=0 \mathrm{~m}$ and $t=80 \mathrm{~s}$. It is seen that the fire plume is attached to the ground immediately downstream of the fire front. This phenomenon is a manifestation of Coanda effect. It is also known as the trench effect which has been observed in fires over inclined surface [31,32]. Further downstream, buoyancy force prevails and the plume is lifted above the ground as shown in Fig. 2.

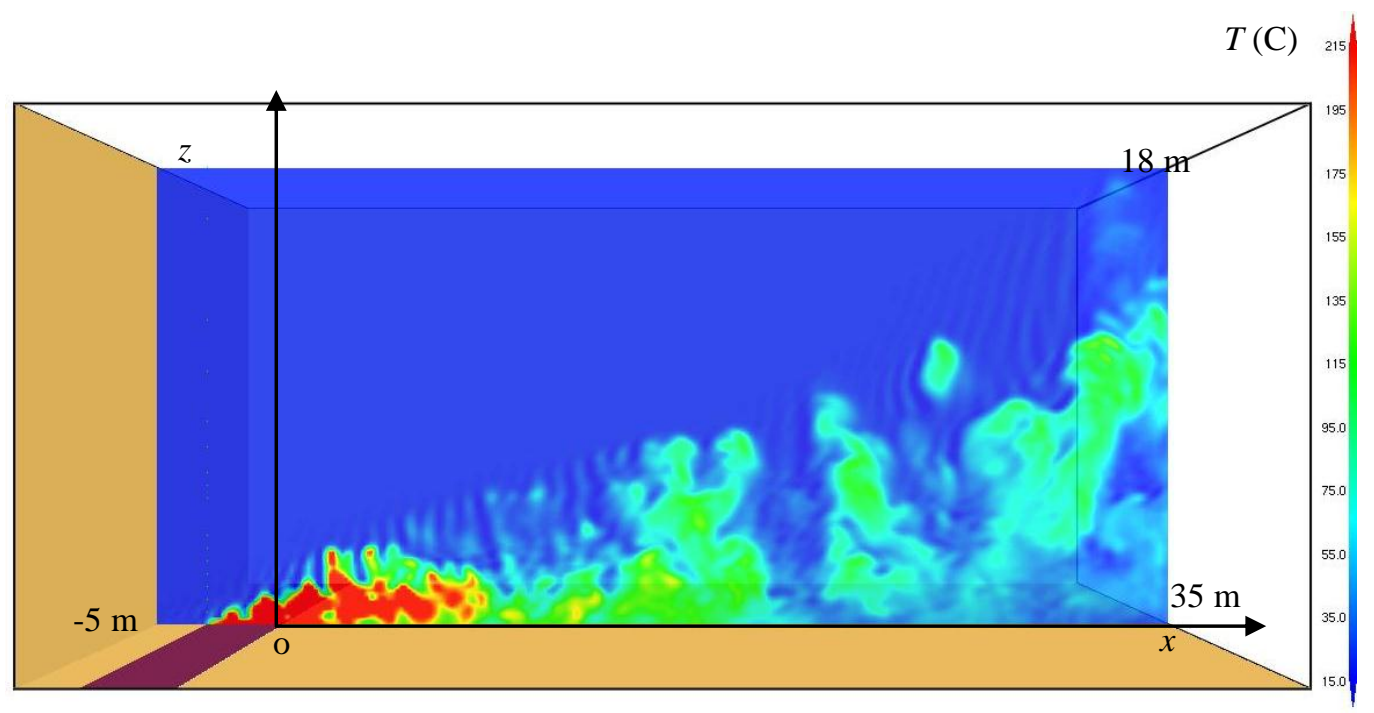

Fig. 2. Temperature slice at $y=0 \mathrm{~m}$ and $t=80 \mathrm{~s}$. 
The $u$-velocity component slice at the same location and time as that in Fig. 2 is present in Fig. 3. Both Fig. 2 and Fig. 3 reveal that there is a pulsating, or flickering movement by the flame. This phenomenon is further analyzed and discussed at the later part of this subsection.

The changes in $u$-velocity profiles are depicted in Fig. 4a where the mean velocity profiles $u^{*}=u / u_{r}$ at $x=5,20$ and $35 \mathrm{~m}$ are significantly distorted from that at free stream. In the near ground region up to $z^{*}=0.7$, velocities at $x=5$ and $20 \mathrm{~m}$ are significantly greater than the free stream velocity at the same elevation. Further downstream at $x=35 \mathrm{~m}$, the $u$-velocity component is always smaller than the free stream reading up to $z^{*}=2$. This change is consistent with the lifting of the plume from the ground as shown in Fig. 2. It is believed that the detachment of the plume from the ground is associated with intermittent reverse flow. This is reflected by the very high "turbulence intensity" shown in Fig. $4 \mathrm{~b}$ for the $x=35 \mathrm{~m}$ case.

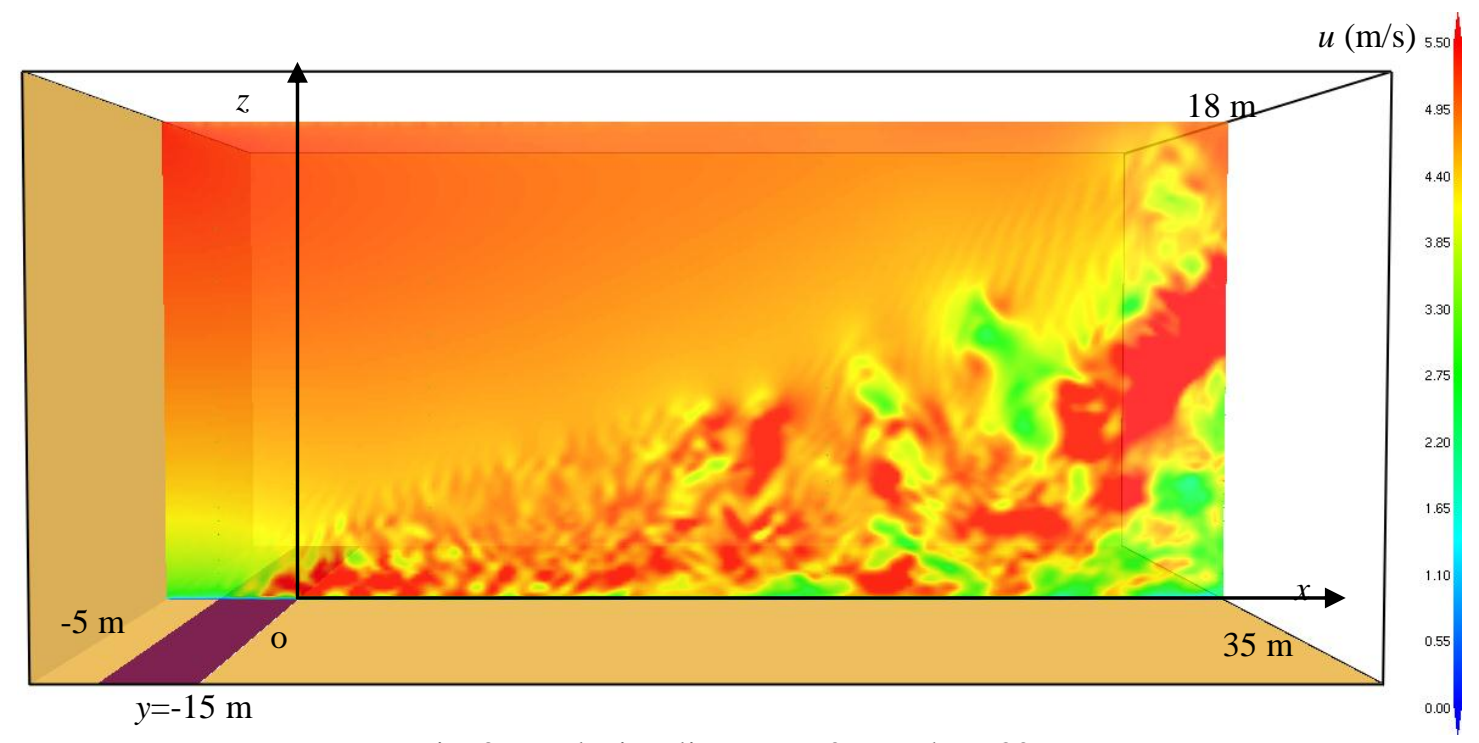

Fig. 3. $u$-velocity slice at $y=0 \mathrm{~m}$ and $t=80 \mathrm{~s}$.

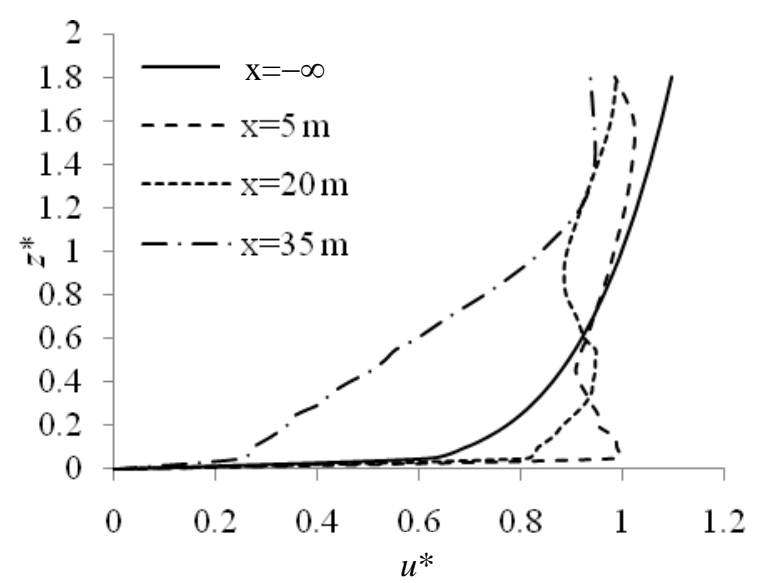

(a)

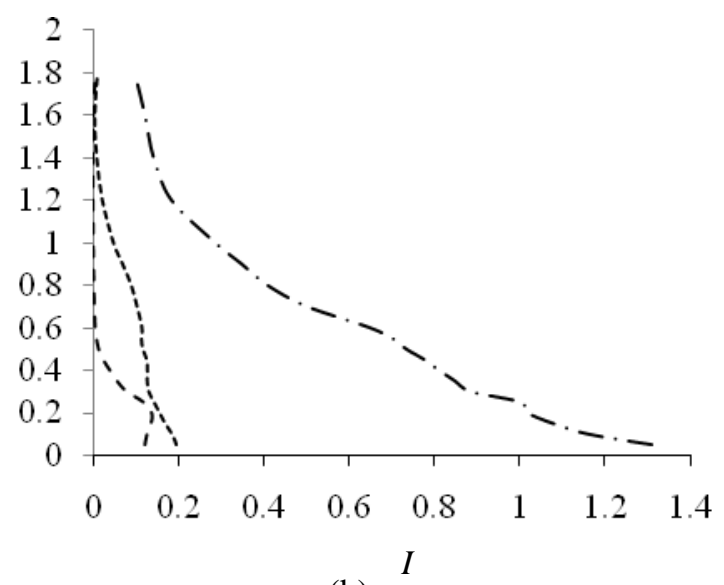

(b)

Fig. 4. Predicted mean velocity and turbulence intensity profiles: (a) mean velocity profiles; (b) turbulence internsity profiles.

The changes in velocity profile indicate the changes in momentum flux. Accompanied with these changes are strong turbulent actions which are revealed in the turbulence intensity profiles shown in Fig. 4b. The corresponding ratio of velocity profiles at given distances $x$ to that at free stream $(x=-\infty)$ and the 
normalized gust velocity profiles are presented in Fig. 5. The gust velocities were determined in accordance with AS/NZS1170.2 [33]:

$\hat{u}^{*}=\frac{u+3.7 \sigma_{u}}{u_{r}}=\frac{u}{u_{r}}+3.7 \frac{\sigma_{u}}{u} \frac{u}{u_{r}}=(1+3.7 I) u^{*}$

It is seen from Fig. 5a that the $u$-velocity component not far downstream of the fire front can be increased by the fire by up to $50 \%$. Evidently, the combined effects of changes to the mean velocity profiles and turbulence intensities resulted in significant increases in gust velocities. It is interesting to note that although the mean velocity at $x=35 \mathrm{~m}$ is less than that at the other two locations (see Fig. 5a), the gust velocity at this location is seen to be greater than at the other two (see Fig. 5b). Caution should be taken when interpreting this result, since intermittent reversal flow cannot be necessarily regarded as truly turbulent flow and, therefore, Eq. 6 may not be applicable to the $x=35 \mathrm{~m}$ case.

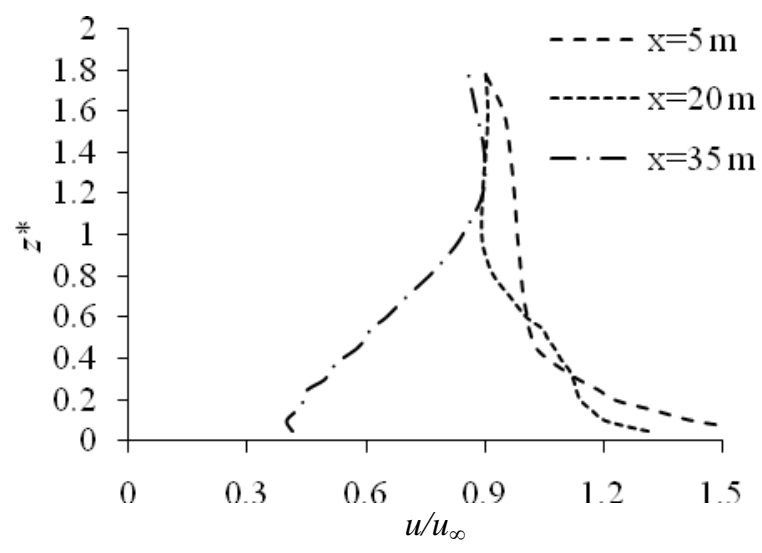

(a)

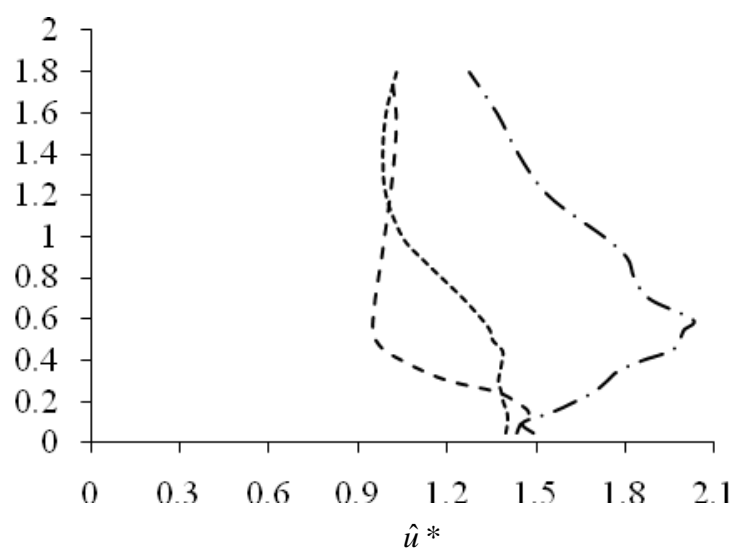

(b)

Fig. 5. Predicted velocity profile ratio and gust velocity profiles: (a) $u$-velocity profile ratios; (b) gust velocity profiles.

A predicted velocity trace as a function of time is shown in Fig. 6 . It took approximately $20 \mathrm{~s}$ for the flow field to establish a quasi-steady state. The velocity trace appears to contain periodic components which may be due to the pulsation, or flickering movement of flames that is observed in pool fires [34] and in fire plumes over inclined surfaces [35].

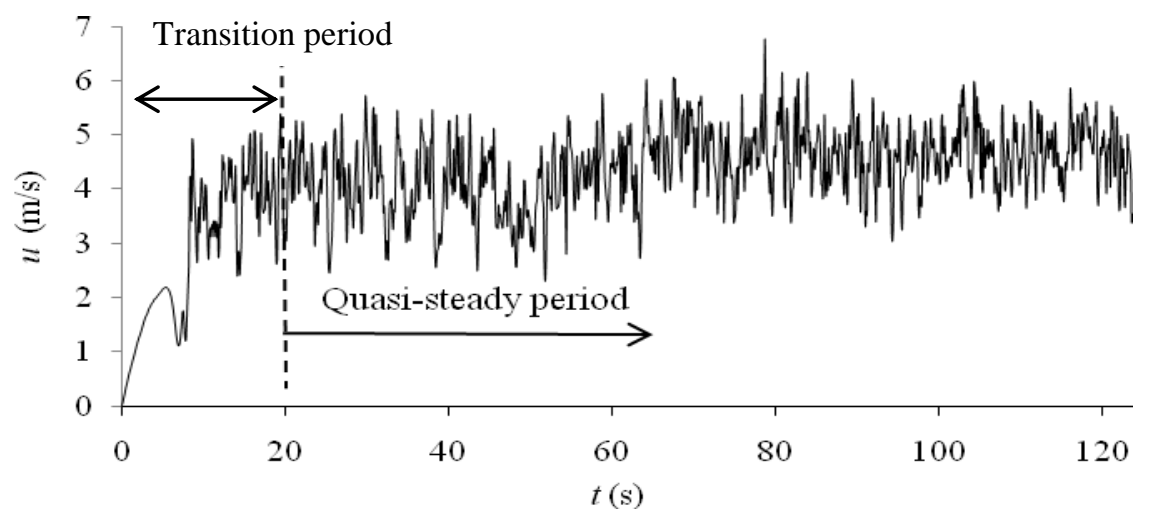

Fig. 6. Predicted velocity variations at $(5,0,2)$.

To identify the signature frequency of the flickering, fast Fourier transform was performed to the posttransition fluctuating velocity components at two locations $(5,0,0.5),(5,0,3),(5,0,5)$ and $(5,0,8)$ and 
the respective normalized non-dimensional power spectra are shown in Fig. 7. At the near ground level $(z=0.5 \mathrm{~m})$, there appears a dominant frequency of $2.5 \mathrm{~Hz}$ as shown in Fig. 7a. Further away from the ground at an elevation of $3 \mathrm{~m}$, the signature frequency is submerged in a broader spectrum as in Fig. $7 \mathrm{~b}$ that reflects the background broadband buoyancy enhanced turbulent interactions. Further up near the upper boundary of the plume $(z=5 \mathrm{~m}$, see Fig. 3 ) the dominant frequency is shifted to somewhere close to $5 \mathrm{~Hz}$ as shown in Fig. 7c. Outside of the plume $(z=8 \mathrm{~m})$ there is hardly any dominant frequencies.

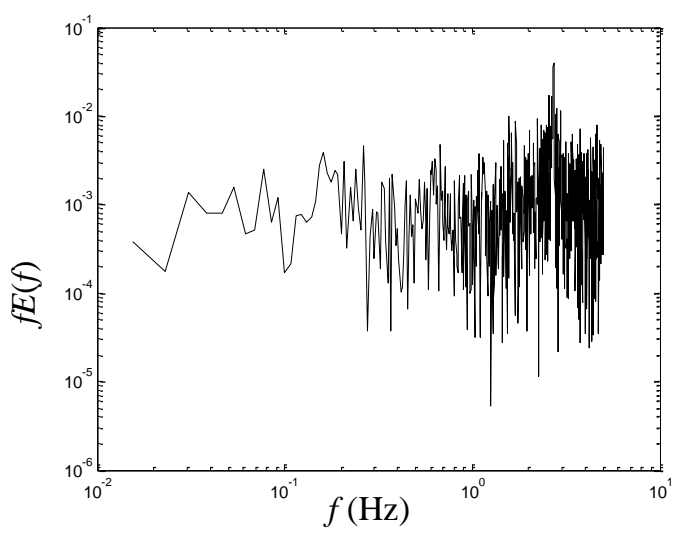

(a)

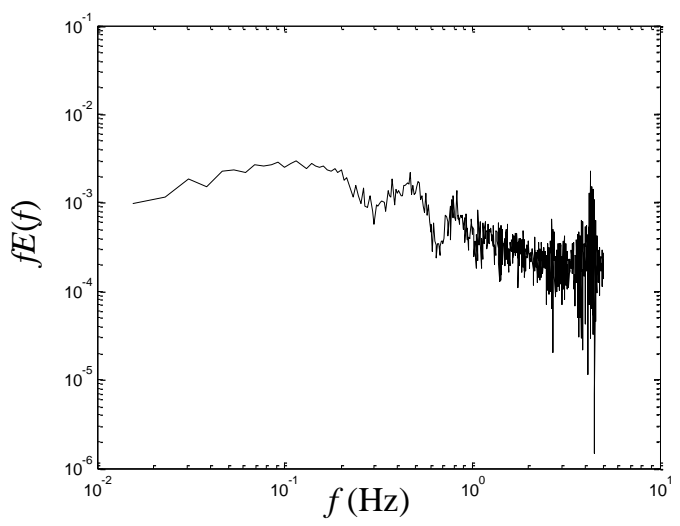

(c)

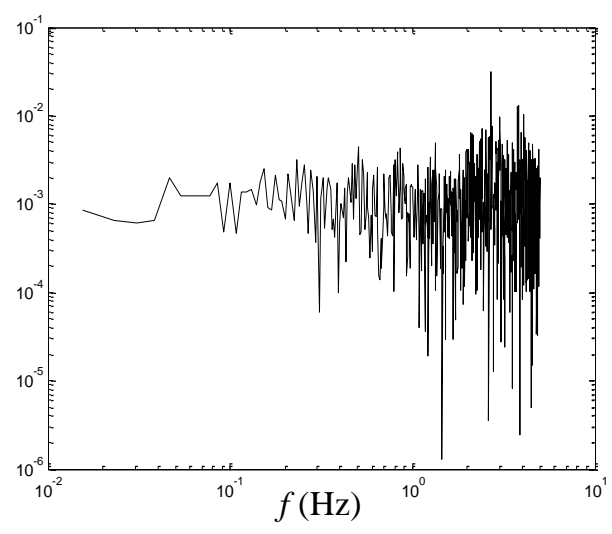

(b)

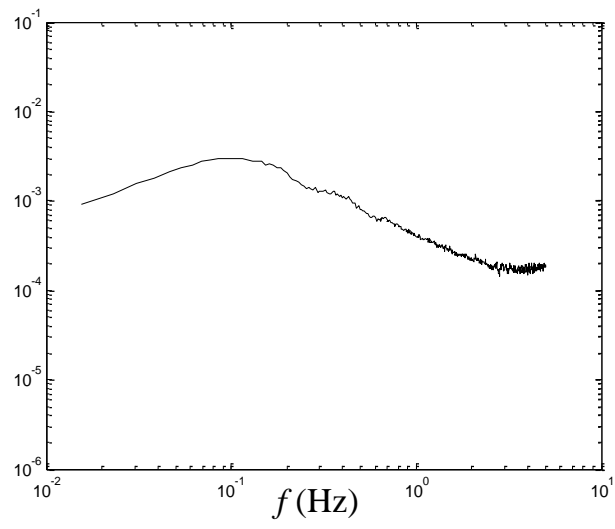

(d)

Fig. 7. Normalized dimensionless turbulence power spectra: (a) at $(5,0,0.5)$; (b) at $(5,0,3)$; (c) at $(5,0,5)$; (d) at $(5,0,8)$.

\section{Wind-Fire-Structure Interactions}

\section{Model Description and Simulation Scenarios}

The numerical investigation of wind-fire-structure interactions was conducted in two steps. Since experimental results of pressure coefficient distributions around buildings are available in the literature for no-fire conditions, the simulation scenario in the first step involved no fires. The experimentally measured free stream condition was used as input to the simulation model and the outputs of the simulation are compared with the published data for verification or validation. Then in the second step, multiple simulation scenarios were carried out under different fire and wind conditions.

A building block of $6 \times 6 \times 6 \mathrm{~m}(L \times W \times H)$ was placed at a distance of $25 \mathrm{~m}$ downstream of the upstream boundary, or $20 \mathrm{~m}$ downstream of the fire front. This block is the same as the cube used by Richards et al. [36] in their full scale experimental study of pressure distribution due to wind. The measured free stream velocity profile by Richard et al. was fitted with the expression as in Eq. 1 with $u_{r}=9.52 \mathrm{~m} / \mathrm{s}, z_{r}=H=6 \mathrm{~m}$ and $\alpha=0.16$, see Fig. 8. The resulting correlation coefficient is 0.999 . The fitted curve was then used as an input boundary condition for the model simulation. 


\section{Grid Dependence Study}

A grid dependence study was carried out in conjunction with the verification of the numerical results with experimental data. In this study four simulation runs with different cell sizes were conducted. The grid sizes utilized in the four models are as shown in Table 1.

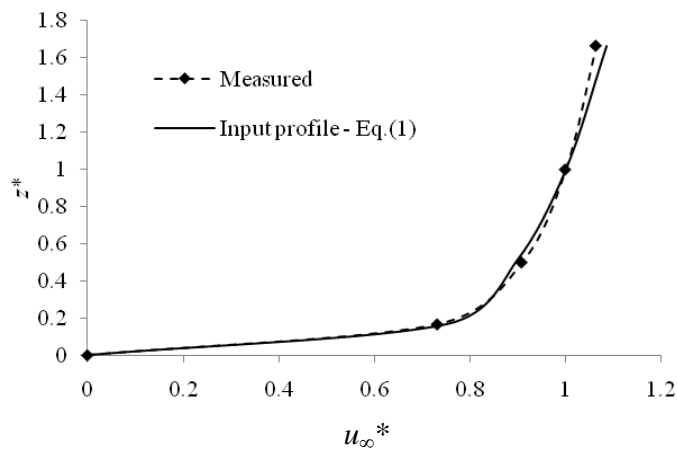

Fig. 8. Free stream velocity profiles.

Table 1. Summary of grid sizes used for grid sensitivity study.

\begin{tabular}{|c|c|c|c|c|c|}
\hline \multirow{2}{*}{ Simulation ID } & \multicolumn{3}{|c|}{ Grid Sizes (m) } & \multirow{2}{*}{$\begin{array}{c}\text { Total number } \\
\text { of cells }\end{array}$} & \multirow{2}{*}{ Comments } \\
\cline { 2 - 4 } & $\boldsymbol{\delta} \boldsymbol{x}$ & $\boldsymbol{\delta} \boldsymbol{y}$ & $\boldsymbol{\delta} \boldsymbol{z}$ & 172,800 & Uniform \\
\hline M1 & 0.5 & 0.5 & 0.5 & $1,382,400$ & Uniform \\
\hline M2 & 0.25 & 0.25 & 0.25 & $2,880,000$ & Non-uniform \\
\hline M3 & 0.17 & $0.24 / 0.42$ & 0.15 & Non-uniform \\
\hline M4 & 0.17 & $0.2 / 0.35$ & 0.15 & $3,456,000$ & Non-uniform \\
\hline M5 & 0.17 & $0.15 / 0.26$ & 0.15 & $4,608,000$ & \\
\hline
\end{tabular}

In the case of a non-uniform grid, a piecewise linear transformation was specified for the $y$-direction grid. The transformation resulted in finer grids at the centre region $(-8 \mathrm{~m}<\mathrm{y}<8 \mathrm{~m})$ of the domain and coarser grid size elsewhere $(-15 \mathrm{~m}<\mathrm{y}<-8 \mathrm{~m}$ and $8 \mathrm{~m}<\mathrm{y}<15 \mathrm{~m})$. The results of the grid sensitivity study are presented in Fig. 9. In this figure the non-dimensional parameter $s^{*}$ is defined as $s^{*}=s / H$. The pressure coefficient data are the average values over the quasi-steady period.

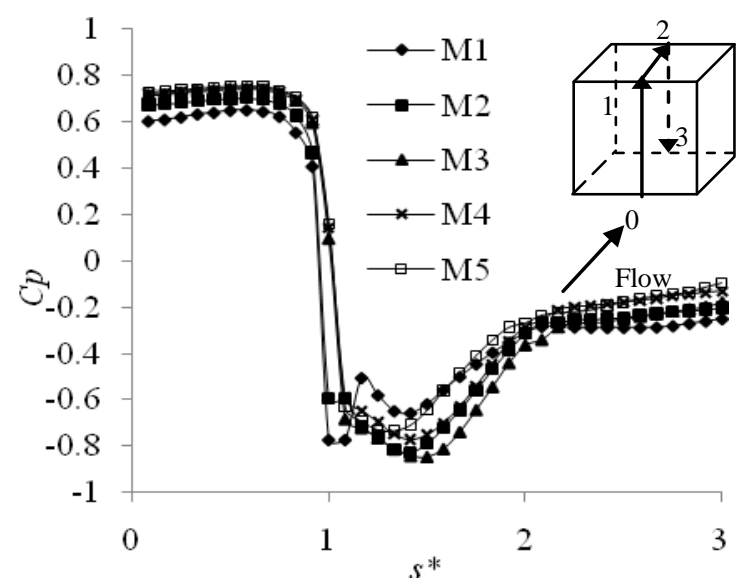

(a)

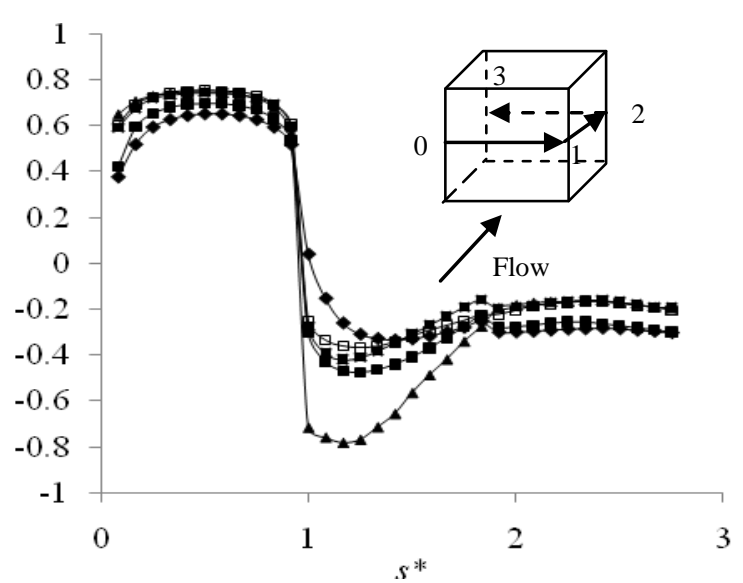

(b)

Fig. 9. Variation of the predicted pressure coefficient distribution with grid size: (a) centerline;

(b) mid-height. 
It can be observed from Fig. 9a that the pressure coefficient distribution results from the model using $0.25 \mathrm{~m}$ cell size (M2) down to a $0.15 \mathrm{~m}$ cell size (M5) do not significantly differ. This indicates the convergence of the results. However significant differences can be observed in the mid height horizontal pressure coefficient distributions in Fig. 9b. In particular the results obtained from M3 model (using $0.24 / 0.46 \mathrm{~m}$ cells in $y$-direction) showed significant negative pressure at the side face of the solid block. While the model with the finest grid size (M5) showed good agreement with the $0.25 \mathrm{~m}$ uniform grid model (M2), the difference between M4 and M5 results are barely noticeable. It is not well understood why the result of the fine M5 agreed better with the results of coarse grids in M1 and M2 than with medium grid M3. Although there was a temptation to choose the coarse M2 grid on the economic ground for further simulations, a further comparison with the experimental results from the literature showed the best agreement with M3. Hence the temptation of using any other grid was ruled out. See result and discussions presented in the following subsection.

\section{Comparison of Numerical Results with Wind Tunnel and Field Measurement}

The predicted pressure distribution profiles using the M3 and M5 grid system are compared with the data from Richards et al.'s [36] (Silsoe) $6 \mathrm{~m}$ cube field measurement in Fig. 10. The wind tunnel measurement data and the numerical results by other workers as reported in Richards et al.'s paper are also included for comparison.

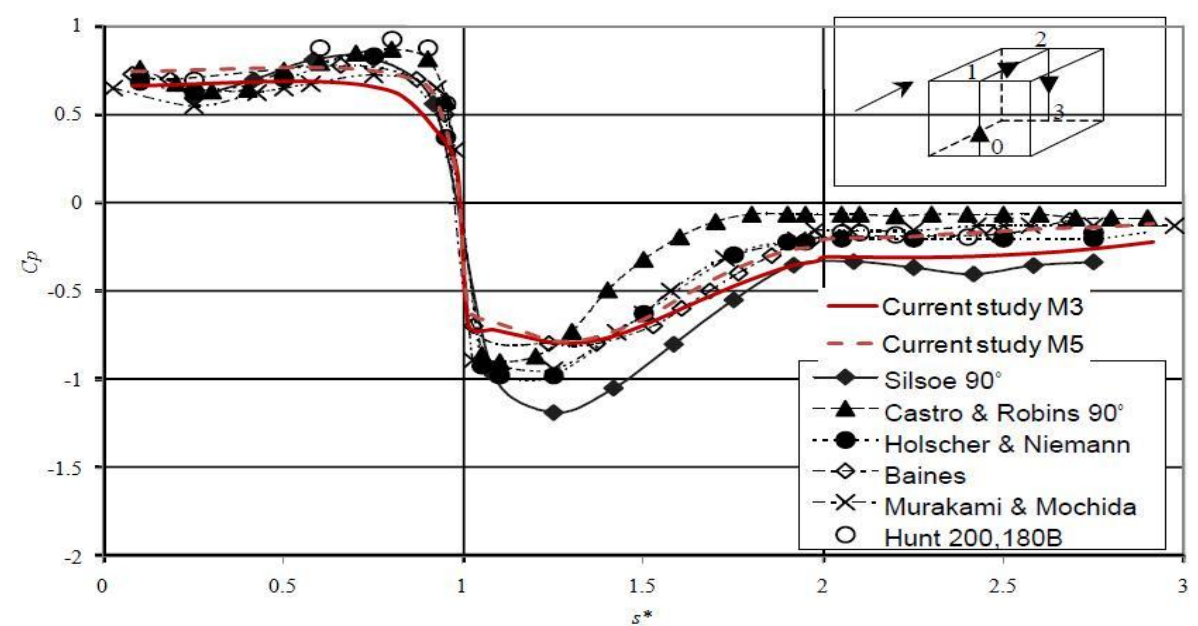

(a)

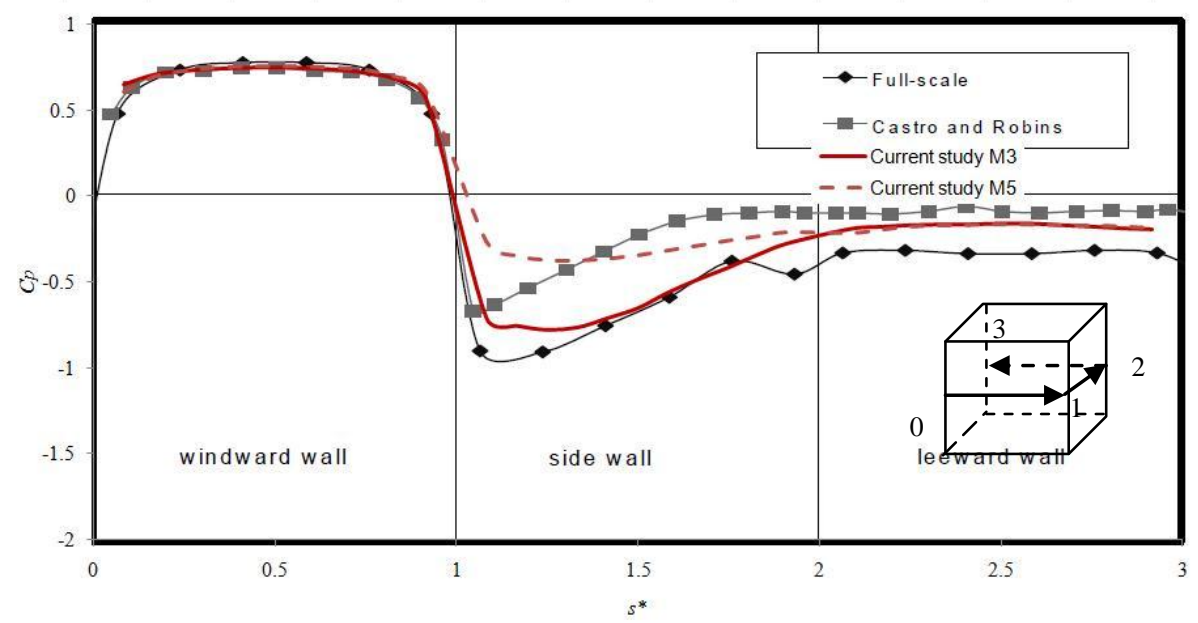

(b)

Fig. 10. Comparison of the current numerical simulation results with the experimental and numerical results reported in Richards et al. [36]: (a) centerline pressure coefficient distribution around the cube; (b) mid-height pressure coefficient distribution around the cube. 
As can be seen from Fig. 10, reasonably good agreement is achieved between the experimental data and model predictions. The difference between the results of the two grids is quite small in the case of centerline distribution. This difference becomes greater in the case of mid height distribution, though still more or less within the difference band of the experimental results.

\section{Effect of Bushfires on the Wind Load over the Building Block}

A parametric study was conducted with varying bushfire intensity to see the effect of fire-enhanced wind on the wind load over the building block. The additional simulation scenarios involved fire intensities of 5.5, 9 and $15 \mathrm{MW} / \mathrm{m}$ whilst the free stream reference velocity was maintained at $9.52 \mathrm{~m} / \mathrm{s}$.

A snapshot of the predicted $u$-velocity field at $t=80 \mathrm{~s}$ is presented in Fig. 11. The impact of the fireinduced wind was found to be most evident on the windward face of the building block where the pressure coefficients, and the corresponding wind-induced load, were significantly increased. This is consistent with the fire-induced wind characteristics shown earlier in Fig. 4 and Fig. 5.

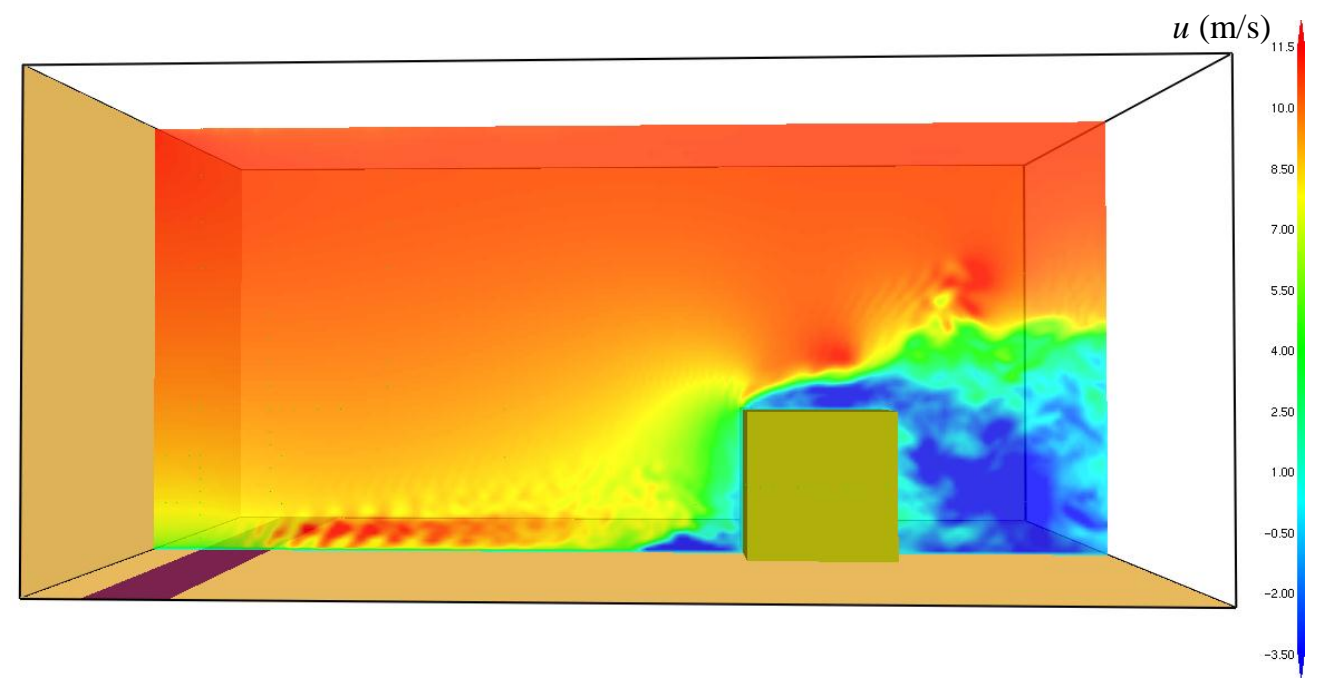

Fig. 11. Velocity field with a building block $(t=80 \mathrm{~s})$.

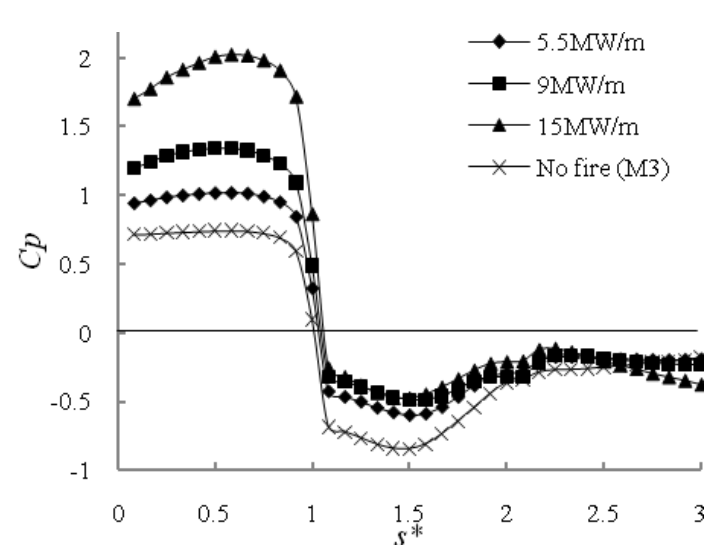

(a)

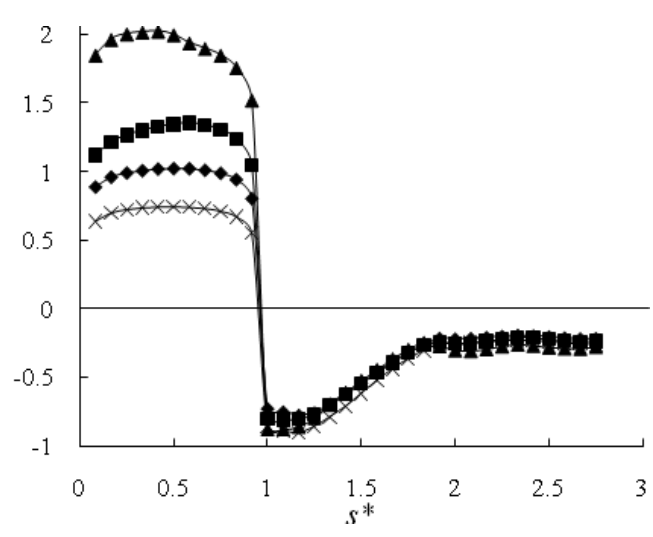

(b)

Fig. 12. The effect of fire intensity on pressure coefficient distributions: (a) centerline; (b) mid-height.

The pressure coefficient distribution results of the aforementioned three simulation scenarios are shown and compared with that under the no-fire condition in Fig. 12. The pressure coefficient profiles, or the shapes, remain qualitatively the same. Quantitatively, the fires enhanced wind velocity in the lower region of the domain and this is evident from the increased pressure coefficient at the windward face of the cube (Fig. 12a). This increase is seen to be in the range of $25 \%$ to $150 \%$ as compared with the no-fire case. 
At the roof side face, there are minor reductions in the uplift pressure (i.e. reduction in the magnitude of the negative pressure coefficient, refer to Fig. 12a). This may be due to the reduction in the velocity over the roof after the enhanced wind flow striking the front face. It can be seen in Fig. 11 that there are negative $u$ velocity regions over the roof and behind the building block.

Little variation has been observed of the pressure coefficient distribution around the side walls and leeward surface of the block. In fact there are slight decreases in the pressure coefficient at the leeward face with the increasing fire intensity. See Fig. 12a and Fig. 12b. The overall effect of the fires is the increased wind load over the entire building block. This leads to the conclusion that apart from the radiant heat and ember attacks, bushfires aid the destructive force of wind. The more intense of the bushfire front, the greater is the destructive force.

\section{CONCLUSION}

Bushfires under extreme conditions of weather and fuel give rise to increased fire behavior out of proportion with the ambient conditions normally associated with bushfire events. It has been shown through numerical simulations that the interactions between wind and bushfire produce strong local effect at near ground level, or at the scales that are comparable to building sizes. The combined momentum and buoyancy flux can distort the wind velocity profile in a very dramatic manner such that the wind speed at near ground elevation is increased by more than $50 \%$ at a given distance downstream of a modest fire front. The wind-fire interactions also produce strong turbulence and wind gust of twice the upstream velocity can be observed. As a consequence, the pressure coefficient distribution, or the wind load, over the surface of the building block downstream of the bushfire front is increased significantly.

The numerical simulation also revealed a flickering motion of the fire plume and the aftermath of this flickering motion downstream of the fire front. These results will have major implications for building protection against bushfire attacks. The pulsation movement of the smoke plume can exacerbate the wind load on building elements and structures.

In general, the destructive force of bushfire enhanced wind is proportional to the fire intensity. The wind load needs to be considered in the building standards for bushfire prone areas.

This paper presents the outcomes of numerical simulations of wind-fire interactions near ground at a scale comparable with buildings. It is noteworthy that the use of Fire Dynamics Simulator to study aerodynamic impact of fire enhanced wind on a building was a pioneering attempt. The software has not been specifically and fully validated for such a purpose. The comparison with the full scale experimental data obtained from the literature was only a partial validation since no fire was involved in the experiment. The scope of the current study focused on a limited parametric study with simulation scenarios that did not necessarily reflect precisely real fire scenarios. Nevertheless, the results of the numerical simulation and the post-processing revealed some interesting phenomena which await further investigation, confirmation, verification or validation from laboratory and field experiments.

The set-up of the computation domain and specification of boundary conditions in the current study were governed by computation economy considerations. The grid dependence "hump", or the phenomenon of the medium density grid producing better agreement with experimental data than either the coarse or fine grid, deserve further attention in future numerical studies. Furthermore, the wind-fire interaction has been assumed to dominate local turbulence generation. The extent of the influences of upstream fluctuating component of wind velocity and of thermal radiation calculation with a fine computation grid on the windfire-structure interaction needs to be properly investigated.

Further investigations are also required to unveil the air entrainment flow and the mechanism of the flickering motion and its relationship with the wind speed, fire dimension and fire intensity.

\section{REFERENCES}

[1] Sharples, J.J., (2009) An overview of mountain meteorological effects relevant to fire behaviour and bushfire risk, International Journal of Wildland Fire, 18:737-754. http://dx.doi.org/10.1071/WF08041 
[2] Sharples, J.J., Mills, G. A., McRae, R. H. D., and Weber R. O., "Fire danger anomalies associated with Foehn-like winds in southeastern Australia," in Proceedings of the $18^{\text {th }}$ World IMAC/MODSIM Congress. 2009.

[3] Byram, G.M., "Combustion of forest fuels," in Forest fire: control and use, K.P. Davis, Editor. 1959, McGraw-Hill: New York. p. 61-89.

[4] Byram, G.M., "Atmospheric conditions related to blowup fires," USDA Forest Service Research Paper SE-35, 1954.

[5] Andrews, P.L., Loftsgaarden, D. O., and Bradshaw, L. S., (2003) Evaluation of fire danger rating indexes using logistic regression and percentile analysis, International Journal of Wildland Fire, 12(2):213-226. http://dx.doi.org/10.1071/WF02059

[6] Noble, I.R., Bary, G. A. V., and Gill, A. M., (1980) McArthur's fire-danger meters expressed as equations, Australian Journal of Ecology, 5:201-203. http://dx.doi.org/10.1111/j.14429993.1980.tb01243.x

[7] Blanchi, R., and Leonard, J., "Investigation of bushfire attack mechanisms resulting in house loss in the ACT bushfire 2003", Report for Bushfire CRC. 2005, CSIRO Manufacturing and Infrastructure Technology: Melbourne.

[8] ABCB, Building Code of Australia. 2010, Australian Building Codes Board: Canberra, Australia.

[9] AS3959, Construction of Buildings in Bushfire-prone Areas. 2009, Standards Australia.

[10] Sullivan, A., Nature of Severe Fire Events, Client Report for Fire Management Unit, Department of Urban Services, ACT Government, Commonwealth Science and Industry Research Organisation, Canberra, 2004.

[11] Ahern, A., and Chladil, M., "How far do bushfires penetrate urban areas?" in Procceedings of Australian Disaster Conference, Emergency Management Australia: Canberra, Australia, 1999.

[12] Douglas, G., Tan, Z., Midgley, S., and Short, L., (2009) Bushfire building damage - A NSW perspective. Proceedings of Royal Society of Queensland, 115:161-169.

[13] McAneney, J., Chen, K., Crompton, R., and Pitman, A. J., Australian bushfire losses: Past, present and future, in Wildfire. 2007: Seville, Spain.

[14] Barrow, G.J., (1945) A survey of houses affected in the Beaumaris Fire, January 14, 1944, Journal of the Council for Scientific and Industrial Research, 18(1).

[15] Ramsay, G.C., McArthur, N.A., and Dowling, V., (1987) Preliminary results from an examination of house survival in the 16 February 1983 bushfires in Australia, Fire and Materials, 11:49-51. http://dx.doi.org/10.1002/fam.810110105

[16] RFS, Planning for Bushfire Protection, New South Wales Rural Fire Service: Sydney, 2001.

[17] BCRC, Victorian 2009 Bushfires Research Response: Final Report. Bushfire Cooperative Research Centre, 2009.

[18] Parkyn, K., Yeo, C. and Bannister T., Meteorological lessons learned from 'Black Saturday', the 7 February 2009 Victoria fires. Proceedings of the $17^{\text {th }}$ Annual AFAC Conference and the $7^{\text {th }}$ Bushfire CRC Conference, Darwin, Australia, 2010.

[19] Church, C.R., Snow, J.T., and Dessens, J., (1980) Intense atmospheric vortices associated with a 1000 MW fire, Bulletin of the American Meteorological Society, 61: p. 682-694, http://dx.doi.org/10.1175/1520-0477(1980)061<0682:IAVAWA>2.0.CO;2

[20] Dold, J.W., Weber, R. O., Gill, M., McRae, R., and Cooper, N., "Unusual phenomena in an extreme bushfire," Proceedings of the $5^{\text {th }}$ Asia-Pacific Conference on Combustion. Adelaide, Australia. 2005, p. 309-312.

[21] Nelson, J.R.M., (2003) Power of the fire - A thermodynamic analysis. International Journal of Wildland Fire, 12: p. 51-65, http://dx.doi.org/10.1071/WF02032 
[22] Cunningham, P, Goodrick, S.L., Hussaini, M.Y., and Linn, R.R. 2005, Coherent vortical structures in numerical simulations of buoyant plumes from wildland fires, International Journal of Wildland Fire, 14: 61-75. http://dx.doi.org/10.1071/WF04044

[23] Coen, J.L., (2005) Simulation of the Big Elk Fire using coupled atmosphere-fire modeling, International Journal of Wildland Fire, 14:49-59. http://dx.doi.org/10.1071/WF04047

[24] Cheney, N.P., Gould, J.S., and Catchople, W.R., (1993) The influence of fuel, weather, and fire shape variables on fire-spread in grasslands, International Journal of Wildland Fire, 3:31-44, http://dx.doi.org/10.1071/WF9930031

[25] Clark, T.L., Jenkins, M.A., Coen, J., and Jackham, D., (1996) A coupled atmospheric-fire model: convective feedback on fire line dynamics, Journal of Applied Meteorology, 35:875-901, http://dx.doi.org/10.1175/1520-0450(1996)035<0875:ACAMCF>2.0.CO;2

[26] Hostikka, S., Mangs, J. and Mikkola, E., 2009. Comparison of Two and Three Dimensional Simulations of Fires at Wildland Urban Interface. Fire Safety Science 9: 1353-1364. http://dx.doi.org/10.3801/IAFSS.FSS.9-1353

[27] Douglas, G.B., He, Y., and Kwok, K.C.S., "Wind Impacts on Fire Spread and Structural Failure in a Complex Terrain", Proceedings of $14^{\text {th }}$ Australasian Wind Engineering Society Workshop, Canberra, 2010, pp. 91-4.

[28] Kwok, K.C.S., He, Y. and Douglas, G.B., "Wind impacts on fire spread and structural failure during bushfire in complex terrain", Proceedings of $9^{\text {th }}$ United Kingdom Conference on Wind Engineering, Bristol, UK, 20-22 September 2010, pp. 3-14

[29] McGrattan, K., McDermott, R., Hostikka, S., and Floyd, J., Fire Dynamics Simulator (Version 5) User's Guide. 2010, NIST Special Publication 1019-5, National Institute of Standards and Technology.

[30] McGrattan, K., Baum, H., Rehm, R., Mell, W., and McDermott, R., Fire Dynamic Simulator (Version 5) Technical Reference Guide. 2010, NIST Special Publication 1018-5, National Institute of Standards and Technology.

[31] Simcox, S., Wilkes, N.S., and Jones, I.P., (1992) Computer simulation of the flows of hot gases from the fire at King's Cross underground station. Fire Safety Journal, 18:49-73, http://dx.doi.org/10.1016/0379-7112(92)90047-G

[32] Drysdale, D.D., Macmillan, A.J.R., and Shilitto, D., (1992) King's Cross fire: Experimental verification of the 'Trench Effect'. Fire Safety Journal, 18(1):75-82, http://dx.doi.org/10.1016/0379-7112(92)90048-H

[33] AS/NZS1170.2, Structural design actions Part 2: Wind actions. 2002, Standards Australia: Sydney.

[34] Hamins, A., Yang, J.C., and Kashiwagi, T. (1992) An experimental investigation of the pulsation frequency of flames, Symposium (International) on Combustion 24(1): 1695-1702. http://dx.doi.org/10.1016/S0082-0784(06)80198-0

[35] Woodburn, P.J., and Drysdale, D.D., (1998) Fires in inclined trenches: Time-varying features of the attached plume. Fire Safety Journal, 31(2): p. 165-172. http://dx.doi.org/10.1016/S0379$\underline{7112(98) 00003-4}$

[36] Richards, P.J., Hoxey, R.P., and Short, L.J., (2001) Wind pressures on a 6m cube. Journal of Wind Engineering and Industrial Aerodynamics, 89:1553-1564. http://dx.doi.org/10.1016/S0167$\underline{6105(01) 00139-8}$ 